It was therefore decided to use a solution containing less electrolyte, and half-strength Darrow's solution was found to be most suitable. It is important, therefore, for persons engaged in rehydrating babies in developing countries to be acquainted with the clinical presentation of children with hypertonic dehydration, and to avoid using hypertonic solutions such as normal saline or full-strength Darrow's solution intraperitoneally in these babies.

With all the solutions used there was significant absorption of potassium ion. This, we believe, was due to its high diffusion constant and concentration gradient. The peritoneal membrane behaves in a non-selective manner and allows diffusion of electrolytes between it and the blood according to their concentration gradient.

\section{REFERENCES}

Blackfan, D. K., and Maxcy, K. F. (1918). American fournal of Diseases of Children, 15, 19.

Carter, F. S. (1953). East African Medical fournal, 30, 499.

Jelliffe, D. B. (1961). Fournal of Tropical Paediatrics, 7, 29.

Moore, F. D. (1959). Metabolic Care of the Surgical Patient. Philadelphia, Saunders.

\title{
Clinical Evaluation of Adriamycin, a New Antitumour Antibiotic
}

\author{
GIANNI BONADONNA,* M.D.; SILVIO MONFARDINI, $\dagger$ M.D.; MARIO DE LENA, $\ddagger$ M.D. \\ FRANCA FOSSATI-BELLANI, $\ddagger$ M.D.
}

British Medical Fournal, 1969, 3, 503-506

\begin{abstract}
Qummary : Adriamycin, a new antitumour antibiotic of the anthracycline group with a structural formula very similar to daunorubicin, has proved to have potent tumour-growth-inhibiting properties, and to be particularly effective in childhood malignancies. Though adriamycin produces a higher percentage of side-effects than daunorubicin-namely, stomatitis and alopecia-a lower dosage may be used for therapy.
\end{abstract}

\section{Introduction}

Adriamycin is a new antibiotic isolated in 1967 in the Farmitalia Research Laboratories from cultures of a mutant Streptomyces peucetius (Streptomyces peucetius caesius). The chemical structure of this compound (Arcamone, Cassinelli, Di Marco, and Gaetani, 1967) is very similar to that of daunomycin, from which is differs only in the substitution of a hydrogen atom with a hydroxyl group on the acetyl radical (Fig. 1). In acid media adriamycin is split into two components, a red pigmented water-insoluble aglycone (adriamycinone) and a water-soluble basis-reducing amino-sugar (daunosamine). Adriamycin belongs to the anthracycline group, as do daunomycin and rubidomycin (daunorubicin).

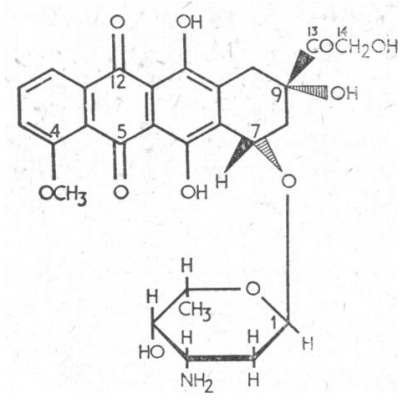

FIG. 1.-Structural formula of adriamycin.

The preliminary pharmacological studies were carried out by Di Marco, Gaetani, and Scarpinato (1969) at the National Cancer Institute of Milan. Adriamycin shows in some mouse and rat tumours a pronounced inhibitory effect on neoplastic proliferation followed by increased survival. Comparative studies showed that at equitoxic doses $(2$ and $2.5 \mathrm{mg}$. of adria- mycin per $\mathrm{kg}$. and 2.6 and $3.25 \mathrm{mg}$. of daunomycin per $\mathrm{kg}$.) the survival time in $\mathrm{C} 3 \mathrm{H}$ mice bearing lymphosarcoma was higher in animals given adriamycin, while the inhibiting dose $\left(\mathrm{ID}_{50}\right)$ was found to be 1.5 and $3.3 \mathrm{mg} . / \mathrm{kg}$. for adriamycin and daunomycin, respectively. The conclusion from these preliminary pharmacological studies is that adriamycin has a higher therapeutic index $(1 \cdot 25)$ than daunomycin $(0 \cdot 67)$. Furthermore, a lesser degree of leucopenia was observed in rabbits with adriamycin than with daunomycin, with the same dosage. A mild tachycardia without electrocardiographic abnormalities was recorded only in those rabbits controlled after two months (Bertazzoli, Chieli, Dell'Oro, Ferni, and Ricevuti, 1968).

The initial studies in man were started in the Clinical Chemotherapy Unit of the National Cancer Institute of Milan in September 1968. Up until May 196946 patients had been investigated. The pharmacological effects of the drug (dosage, therapeutic schedule, and toxicity) have been described in detail elsewhere (Bonadonna and Monfardini, 1969b).

From the present study adriamycin appears to be a drug which can produce a prompt effect in different types of neoplastic diseases with lower doses than those used with daunorubicin. The initial toxicity is mainly represented by extensive ulcers of the oral mucosa followed almost immediately by bone marrow depression and alopecia. In fewer cases leucopenia or loss of hair may be the first sign of toxicity. No appreciable changes in the liver and renal function tests have been observed, while no consistent cardiac abnormalities have been recorded.

The aim of the present study is to report the objective regressions obtained with adriamycin in leukaemia and in solid tumours of children and adults, as well as the side-effects found.

\section{Materials and Methods}

Thirteen children up to the age of 15 years (nine boys and four girls) and 33 adults with an average age of 47 years (26 men and seven women) have been adequately evaluated. Of the 46 patients reported in this study, 20 had previously received adriamycin and one or more courses of chemotherapy or radiotherapy or both.

Clinical Chemotherapy Unit, National Cancer Institute, Milan, Italy. * Clinical Associate.

$\ddagger$ Clinical Assistant. 
Besides blood counts, bone marrow aspiration, serum uric acid, and liver and renal function tests, electrocardiograms (E.C.G.) were systematically recorded before drug administration and then once or twice weekly during treatment and in particular immediately after the onset of toxicity.

\section{Drug and Mode of Administration}

Adriamycin (a reddish powder supplied in 20-mg. phials and freely soluble in distilled water, physiological saline, or $5 \%$ dextrose in water) has always been given as a rapid single intravenous injection. We gave the drug in three different doses: $0.4 \mathrm{mg}$. $/ \mathrm{kg}$., especially to patients previously treated with other anticancer drugs; $0.65 \mathrm{mg} . / \mathrm{kg}$. to untreated adults; and 0.8 $\mathrm{mg}$. $/ \mathrm{kg}$. mostly to children. Three dose schedules, irrespective of the single dose per kilogramme, were also used:

(1) Loading-dose Schedule.-After an initial dose for four consecutive days the drug was stopped for three days and then restarted once or twice weekly until side-effects occurred.

(2) Alternate-day Schedule.-The drug was injected every other day for four to six doses and then after a three-day interval once or twice weekly until the first sign of toxicity appeared.

(3) Intermittent-dose Schedule.-The drug was injected daily for three consecutive days. After a four-day rest period this course was repeated. After another four-day rest period adriamycin was restarted once or twice weekly until side-effects were evident.

After the patient had recovered from toxicity a maintenance dose was given to most of the patients in the form of one or two injections a week. In five children (four with neuroblastomas and one with an embryonal tumour of the abdomen), after inducing tumour regression with adriamycin, the lesions were irradiated. During this study an adequate dose of adriamycin was defined as that inducing the first sign of toxicity.

\section{Assessment of Results}

The criteria of drug response were always those of objective regression of neoplastic lesions as measured on examination, $x$-ray films, or bone marrow examination. For patients with acute leukaemia the criteria of the Midwest Cooperative Chemotherapy Study Group (Hewlett et al., 1964) were used. For solid tumours Karnofsky's (1961) criteria were adoptedthat is, objective improvement for less than one month, for more than one month but with regression less than half of the initial volume, and for more than one month but with a reduction greater than half.

\section{Results}

The types of neoplastic diseases in children and adults treated with adriamycin and the number of responsive cases are summarized in Tables I, II, and III.

TABLE I.-Adriamycin in Acute and Chronic Leukaemias (Children and

\begin{tabular}{cc|c|c|c|c}
\hline Type of Leukaemia & $\begin{array}{c}\text { Adults }) \\
\begin{array}{c}\text { No. of } \\
\text { Cases } \\
\text { Treated }\end{array}\end{array}$ & Complete & Partial & None \\
\hline Acute lymphoblastic & $\cdots$ & 5 & 1 & 2 & 2 \\
Chronic myeloid & $\cdots$ & 2 & 1 & 1 & Remission \\
Chronic lymphocytic & $\cdots$ & 1 & 1 & 3 & 2
\end{tabular}

\begin{tabular}{|c|c|c|c|c|c|c|}
\hline \multirow{2}{*}{ Neoplastic Disease } & \multirow{2}{*}{$\begin{array}{c}\text { No. of } \\
\text { Cases } \\
\text { Treated }\end{array}$} & \multirow{2}{*}{$\begin{array}{l}\text { Respon- } \\
\text { sive } \\
\text { Cases }\end{array}$} & \multicolumn{2}{|c|}{ Remission } & \multicolumn{2}{|c|}{ Duration } \\
\hline & & & $<50 \%$ & $>50 \%$ & $<1$ Month & $>1$ Month \\
\hline $\begin{array}{l}\text { Lymphosarcoma } \\
\text { Neuroblastoma } \ldots \\
\text { Wilms's tumour ... } \\
\text { Embryonal tumour } \\
\text { Fibrosarcoma } \quad . \\
\text { Osteosarcoma } \quad \ldots\end{array}$ & $\begin{array}{l}1 \\
5 \\
1 \\
1 \\
1 \\
1 \\
\end{array}$ & $\begin{array}{l}1 \\
4 \\
1 \\
1 \\
1 \\
0 \\
\end{array}$ & 1 & $\begin{array}{l}4 \\
1 \\
1 \\
1\end{array}$ & 1 & $\begin{array}{l}4^{*} \\
1 \\
1^{*} \\
1\end{array}$ \\
\hline Total & 10 & 8 & 1 & 7 & 1 & 7 \\
\hline
\end{tabular}

TABLE III.-Adriamycin in Adults with Solid Tumours

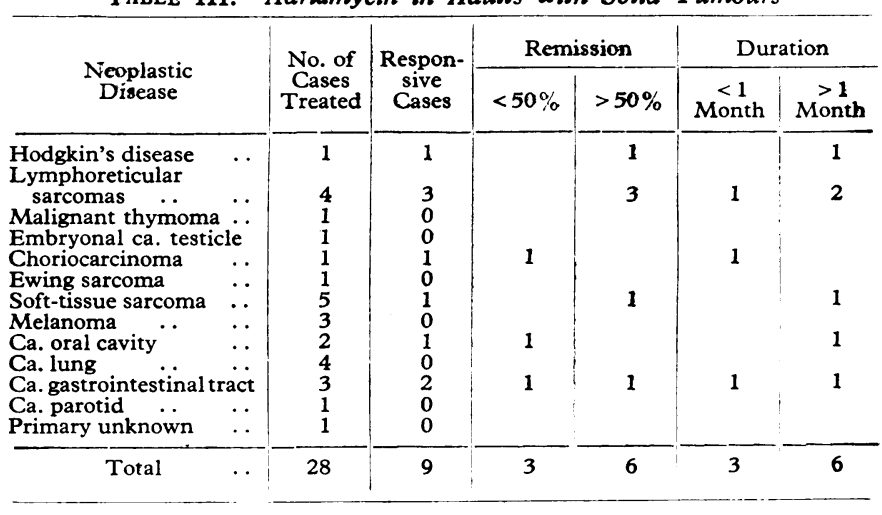

\section{Acute Leukaemia}

Three children with acute lymphoblastic leukaemia had been previously treated with other conventional agents. Of these, one had relapsed after treatment with methotrexate; she had a complete haematological remission (marrow 1) after a few small doses of adriamycin (total $1.85 \mathrm{mg}$./kg.) (Fig. 2). Because of recurrent symptoms of meningeal infiltration intrathecal methotrexate was given with success. Bone marrow relapse, however, was evident within four weeks from the last dose of adriamycin.

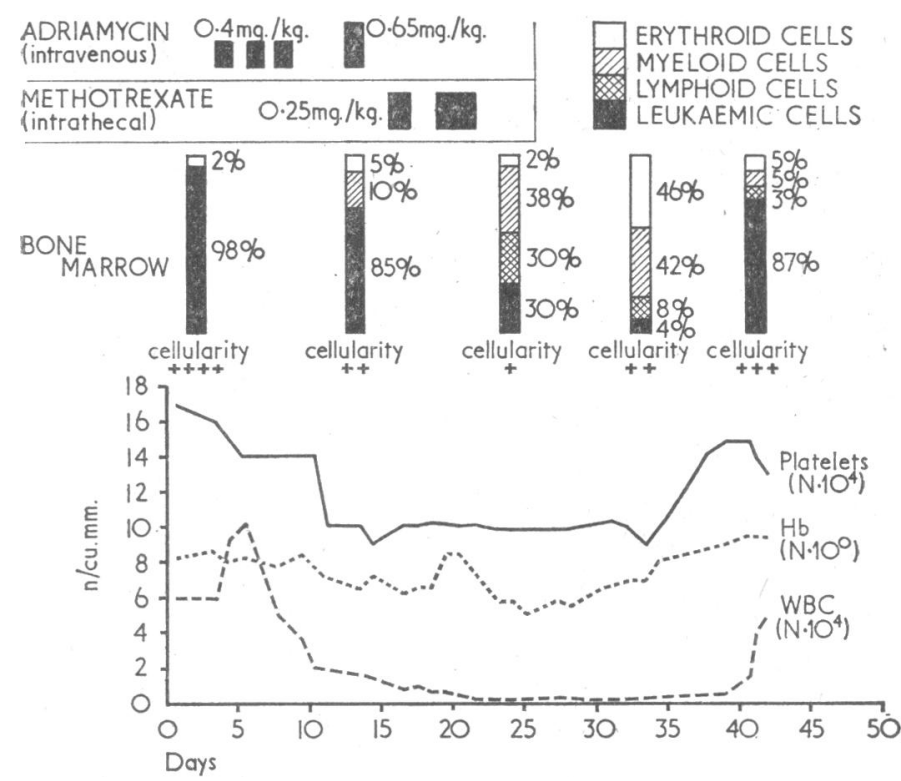

FIG. 2.-Clinical course of a 9-year-old girl with relapsing acute lymphoblastic leukaemia ; complete haematological remission after administration of adriamycin.

The second child, aged 14 years, who had been treated with mercaptopurine in another hospital, had a good partial remission (marrow 2), which occurred after six doses of $0.8 \mathrm{mg} . / \mathrm{kg}$. (loading-dose schedule) (total $4.8 \mathrm{mg}$. $/ \mathrm{kg}$.) had been given. $\mathrm{He}$ was started on prednisone $50 \mathrm{mg}$./day for 10 days and then given methotrexate $30 \mathrm{mg}$./sq. m. every four days. This treatment produced a complete haematological remission (marrow 1) within one month.

The third child, aged 15 years, had been treated successfully for one year with daunorubicin, prednisone, and vincristine. Because of marrow relapse after about eight months' remission with methotrexate, adriamycin was started at the dose of 0.8 $\mathrm{mg} . / \mathrm{kg}$. (loading-dose schedule) for six doses. Almost complete destruction of the leukaemic cells (marrow 2) occurred after a total of $4.8 \mathrm{mg}$. $/ \mathrm{kg}$. had been given, but this was associated with severe depression of normal white and red cell precursors. This child, whose platelets were low before starting adriamycin $(80,000 / \mathrm{cu} . \mathrm{mm}$.), died soon after from cerebral haemorrhage. 
Of the two adults with acute leukaemia, one was untreated (Fig. 3), while the other' was in relapse after receiving a course of corticosteroids, methotrexate, and mercaptopurine in another hospital. Both these patients received the same dose of adriamycin $(0.65 \mathrm{mg} . / \mathrm{kg} . \times 7)$ with about the same schedule, but despite the prompt reduction in peripheral white blood cells the percentage of blasts and leukaemic cells in the marrow remained unchanged. In both patients stopping the drug led to a prompt increase in the peripheral leukaemic cells, while in one patient (Fig. 3) hydrocortisone was given in addition to adriamycin because of haemorrhages caused by a low platelet count.

\section{Chronic Leukaemia}

The two patients with chronic myeloid leukaemia who were both untreated received two different dosages and schedules. Of these, one was given adriamycin $0.8 \mathrm{mg} . / \mathrm{kg}$. on alternate days for four doses (total $3.2 \mathrm{mg} . / \mathrm{kg}$.), and had a very prompt fall in peripheral white blood cells within two weeks (from 210,000 to $1,200 / \mathrm{cu}$. mm.). This fall was associated with a complete disappearance of hepatosplenomegaly. The white blood cell count returned, however, to $110,000 / \mathrm{cu}$. mm. within three weeks, with moderate splenomegaly. A second course of adriamycin $(0.65 \mathrm{mg}$. $/ \mathrm{kg}$. twice a week for three doses, with a total of $2 \mathrm{mg}$./kg.) was again followed by a rapid fall in peripheral leucocytes to a level of $4,500 / \mathrm{cu}$. $\mathrm{mm}$. and a disappearance of splenomegaly within 15 days. At this point the patient was started on busulphan. The other patient received adriamycin $0.4 \mathrm{mg} . / \mathrm{kg}$. on alternate days for eight doses (total $3.2 \mathrm{mg} . / \mathrm{kg}$.) and also had a fairly rapid decrease in the white cell count within two weeks (from 110,000 to $5,800 / \mathrm{cu}$. mm.), but with little regression of the hepatosplenomegaly.

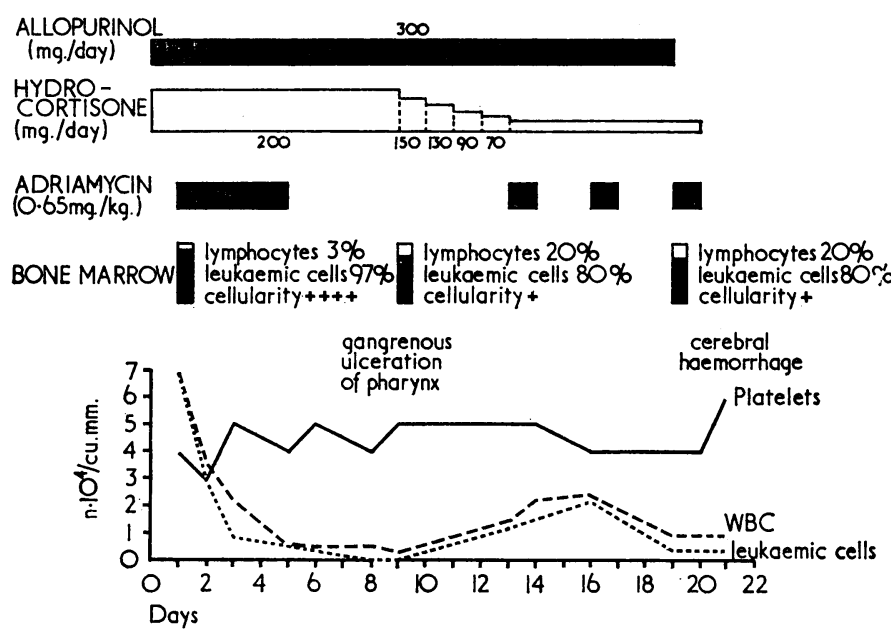

FIG. 3.-Clinical course of a 26-year-old woman with untreated acute lymphoblastic leukaemia who failed to respond to adriamycin treatment.

The patient with chronic lymphocytic leukaemia received a course of adriamycin $0.4 \mathrm{mg}$. $/ \mathrm{kg}$. every other day for a total of seven doses (total $2.8 \mathrm{mg}$. $/ \mathrm{kg}$.). In this instance the prompt and complete regression of splenomegaly and hepatomegaly was followed by a more gradual fall of the peripheral leucocyte count within 18 days (from 20,000 to $6,400 / \mathrm{cu}$. mm.).

\section{Malignant Lymphomas}

A total of six patients were treated (one child and five adults), and of these five responded within a short time (about two weeks). The drug was effective in reducing lymphadenopathy, hepatomegaly, and splenomegaly. With the exception of a child with lymphosarcoma who died within a short period of time from pericardial and pleural effusions, the regressions in tumour size were greater than half of the initial volume.

\section{Other Solid Tumours}

Adriamycin had the greatest effect in children. A prompt regression which was greater than half of the initial volume occurred in the tumours of four out of five children with neuroblastoma. In particular, complete disappearance of pulmonary metastases occurred in one child who was still in remission five months later. Good results also occurred in cases of $\frac{\varrho}{c}$ Wilms's tumour, fibrosarcoma, and in one instance of embryonic tumour of the abdomen. The duration of regression, however, $\stackrel{\vec{\rho}}{\rightarrow}$ was usually short-lived in these cases.

In the adult group consistent regressions were observed in one patient with carcinoma of the oral cavity, in two with $\frac{\bar{D}}{\bar{D}}$ carcinoma of the gastrointestinal tract, in one with rhabdomyo- $\stackrel{\mathbb{}}{\varrho}$ sarcoma, and another with choriocarcinoma. As was the case with the children, the duration of remission was short-lived $\vec{\circ}$ despite maintenance therapy. One patient with a recurrent. carcinoma of the caecum was given maintenance treatment of $\vec{\omega}$ adriamycin $(0.4 \mathrm{mg} . / \mathrm{kg}$. every three weeks) after a reduction $\stackrel{\omega}{\sigma}$ in size of the abdominal mass had been induced, and in this $\frac{5}{3}$ instance the disease remained under control for about six $\frac{3}{\omega}$. months.

\section{Toxicity}

All the patients showed signs of toxicity. Mouth lesions and $\mathrm{c}$ alopecia with cessation of beard growth occurred in all cases, $\omega$ while leucopenia developed in more than two-thirds of the total number (Bonadonna et al., 1969). Diarrhoea occurred in five cases, fever in six, and thrombophlebitis at the site of injection surrounded by a painful indurated area in five. In $\stackrel{\infty}{+}$ 22 out of 46 patients ulceration of the oral mucosa was the $\overrightarrow{\mathscr{\theta}}$ first sign of toxicity, irrespective of the total dose and the schedule given. This sign of toxicity occurred in only three out of 13 children. Stomatitis was followed almost immediately (average one to three days) by leucopenia.

In the present series the mean total dose required to produce the first sign of toxicity was lower in those patients treated $\stackrel{\odot}{\triangle}$ with adriamycin $0.4 \mathrm{mg} . / \mathrm{kg}$. $(2.6 \mathrm{mg} . / \mathrm{kg}$.) and $0.65 \mathrm{mg} . / \mathrm{kg}$. $\stackrel{\varrho}{\Rightarrow}$ $(3.6 \mathrm{mg} . / \mathrm{kg}$.) than in those given $0.8 \mathrm{mg} . / \mathrm{kg}$. $(4.4 \mathrm{mg} . / \mathrm{kg}$.). This could in part be explained by the fact that in the first two groups the average age of the patients was 47 and that most of those treated with adriamycin $0.4 \mathrm{mg} . / \mathrm{kg}$. had already received one or more courses of chemotherapy. On the other hand, the group of patients given $0.8 \mathrm{mg} . / \mathrm{kg}$. included most of the children who, in addition to the patients with acute lymphoblastic $\frac{0}{3}$ leukaemia, had not been treated previously. When considering the drug tolerance in relation to the three different schedules $\delta$ used, the mean initial total dose required to produce the first sign of toxicity was lower in the group receiving the initial treat- $\frac{\text { o }}{7}$ ment on alternate days $(3.1 \mathrm{mg}$. $/ \mathrm{kg}$.) than in that receiving the $\mathrm{N}$ intermittent-dose schedule $(4.6 \mathrm{mg}$. $/ \mathrm{kg}$.). In those receiving or the loading-dose schedule the mean initial toxic schedule was $3.5 \mathrm{mg} . / \mathrm{kg}$. The highest total dose administered in this study was $15 \mathrm{mg} . / \mathrm{kg}$.

Bone marrow cellularity was studied in most patients by means of repeated aspirations from the sternum or from the posterior iliac crest. Depression of myeloid and erythroid pre- $\stackrel{\bullet}{=}$ cursors as well as megakaryocytes was observed in almost every patient in whom leucopenia had developed. Bone marrow hyoplasia, which in some cases was frank aplasia, was especially evident in those patients receiving adriamycin $0.8 \mathrm{mg} . / \mathrm{kg}$. and $\stackrel{\vec{D}}{\stackrel{\mathrm{D}}{ }}$ in those treated with $0.65 \mathrm{mg}$. $/ \mathrm{kg}$. on alternate days. With the $\frac{\rho}{\mathbb{D}}$ exception of one child with acute lymphoblastic leukaemia, who $\cong$ died of cerebral haemorrhage resulting from a low platelet count, the bone marrow depression was always reversible.

Apart from a transient rise in the bromsulphalein retention test at 45 minutes recorded in five patients, no significant changes in electrolytes, blood urea nitrogen, fasting blood sugar, $\stackrel{?}{?}$ liver function tests, and serum electrophoresis which could be attributed to the effects of adriamycin were observed. No 
significant rise in the level of serum uric acid was found, but six out of nine patients with acute or chronic leukaemia received allopurinol throughout the period of drug administration.

E.C.G. changes which occurred in nine adults during treatment with adriamycin consisted primarily of tachycardia and flattened and inverted $\mathrm{T}$ waves. These abnormalities, however, could easily be explained as being secondary to chronic pulmonary insufficiency (resulting from metastases, emphysema, bronchopneumonia), ascites, and anaemia. Only in one instance-a patient with carcinoma of the parotid who was in excellent general condition-were tachycardia and mild flattening of $T$ waves in $V_{2}, V_{4}$, and $V_{6}$ the direct effect of the drug, since these abnormalities disappeared completely after adriamycin was stopped.

\section{Discussion}

Two anthracycline compounds, daunomycin and rubidomycin (daunorubicin), with the same chemical structure have been extensively studied during the past five years and found to have similar biological properties and therapeutic activity (Tan et al., 1967 ; Malpas and Scott, 1968 ; Boiron et al., 1969 ; Holton et al., 1969). Both drugs caused prompt and severe bone marrow depression as well as producing several other toxic effects, such as gastrointestinal disturbances, fever, alopecia, generalized rash, mouth ulceration, and occasional liver disturbances (Tan et al., 1967). Cardiac or cardiopulmonary complications also occurred in some cases, usually after a total dose of $25 \mathrm{mg} . / \mathrm{kg}$. or more (Macrez et al., 1967; Tan et al., 1967 ; Malpas and Scott, 1968). Recently, however, some authors (Bonadonna et al., 1968 ; Bonadonna and Monfardini, 1969a ; Malpas and Scott, 1969; Marmont et al., 1969) observed the occurrence of an acute irreversible cardiac failure with much smaller doses of daunorubicin, and suggested that cardiac toxicity may be dose-independent in adults and that it can occur abruptly even in the absence of E.C.G. abnormalities before drug administration.

Adriamycin, which also belongs to the anthracycline group, has a structure and molecular weight close to that of daunorubicin. Preliminary pharmacological data, however, have demonstrated that adriamycin has a higher therapeutic index than daunorubicin in the same animal tumours. In man, adriamycin produces toxic effects after few doses even when the drug is administered at the single dosage of $0.4 \mathrm{mg} . / \mathrm{kg}$. As expected, children tolerate higher doses than adults. Moreover, patients who have received previous cancer chemotherapy are more susceptible to the toxic side-effects than those who have not. The intermittent-dose schedule seems to have fewer toxic effects, especially in comparison with the alternate-day dose schedule. Though at the present no definite conclusions can be drawn so far as the optimal dose schedule is concerned, we are continuing the clinical evaluation of adriamycin by administering an intermittent-dose schedule of 0.8 and 0.65 $\mathrm{mg}$. $/ \mathrm{kg}$. to respectively untreated children and adults and 0.4 $\mathrm{mg} . / \mathrm{kg}$. to all pretreated patients.

Ulceration of the oral mucosa, bone marrow depression, and alopecia are the most prominent side-effects. All these signs may become very severe whichever dose or schedule is used. If the drug is stopped in time bone marrow depression is transient. Peripheral leucocytes and platelets, with the dosage given in this study, recovered within 8 to 15 days and the oral lesions healed completely in a similar period of time. Loss of hair, on the other hand, is progressive, and despite interruption of treatment toxic doses of adriamycin produce in every patient severe alopecia and complete cessation of beard growth which can last for several weeks (Bonadonna and Monfardini, 1969a). Adriamycin is a vesicant, and occasionally thrombophlebitis or lymphangitis at the site of injection can be observed; it should therefore preferably be injected through the tube of a freely running intravenous infusion. Gastrointestinal disturb- ances (nausea, vomiting, abdominal cramps, and diarrhoea) seem to be of minor importance, at least in our experience.

In the present series and with the total dosage administered, adriamycin seems devoid of significant cardiac toxicity. Some E.C.G. changes (tachycardia, S-T depression, and flattening of $T$ waves) were observed in a few adults during the course of treatment. These usually occurred in patients with widespread disease not responding to treatment. Furthermore, the abnormalities did not increase on further drug administration, nor were they associated with hypotension and dyspnoea as was observed in patients treated with daunorubicin (Bonadonna and Monfardini, 1969a). Since this type of E.C.G. changes without clinical signs of cardiac insufficiency are often seen in patients with widespread malignant tumours, we believe that those observed in this study were probably not directly related to drug effects, but rather to progression of metastatic disease in the lungs or to severe anaemia. In the only patient for whom this interpretation does not seem to be acceptable the E.C.G. abnormalities were very mild and transient, and were not associated with clinical symptoms of heart failure. The problem of cardiac toxicity deserves more extensive study in a larger group of patients.

The administration of adriamycin induced remissions in acute lymphoblastic and chronic (myeloid and lymphocytic) leukaemias as well as in nine histologically different types of solid tumour. In all responsive cases regressions occurred promptly. A definite objective improvement was observed with all doses $(0.4,0.65$, and $0.8 \mathrm{mg} . / \mathrm{kg}$.) and with all types of schedules. The drug appears, therefore, to be a very potent growth-inhibiting compound, and in comparison with daunorubicin lower doses are sufficient to produce therapeutic effects. As already extensively reported with daunorubicin, this preliminary clinical evaluation shows that the regression obtained with adriamycin is usually short-lived, and despite maintenance treatment the neoplastic disease tends to progress after a limited period of time. Furthermore, adriamycin cannot be handled easily as a maintenance drug because of rapidly recurrent toxic effects. Further clinical experience will certainly clarify this point; however, we believe that adriamycin could be classified among those drugs (such as HN2, vincristine, and daunorubicin) which are indicated to induce tumour regression rather than to maintain it.

We are indebted to the Scientific Direction of Farmitalia, Milan, for the generous supply of adriamycin as well as to our colleagues in the Divisions of Radiology, Pathology, and Experimental Biology of the National Cancer Institute, Milan, for their helpful cooperation during this study. We wish to acknowledge also the technical assistance of S. Ceccarini and C. Patti.

Requests for reprints should be addressed to Dr. G. Bonadonna, Via Venezian 1, Milan 20133, Italy.

\section{REFERENCES}

Arcamone, F., Cassinelli, G., di Marco, A., and Gaetani, M. (1967). Patent application Farmitalia Research Laboratories 251 NSA Bertazzoli, C., Chieli, T., Dell'Oro, I., Ferni, G., and Ricevuti, G. (1968). Unpublished data.

Boiron, M., et al. (1969). Lancet, 1, 330.

Bonadonna, G., Monfardini, S., and Guindani, A. (1968). Tumori, 54, 465.

Bonadonna, G., and Monfardini, S. (1969a). Lancet, 1, 837.

Bonadonna, G., and Monfardini, S. (1969b). Cancer Research. In press. Di Marco, A., Gaetani, M., and Scarpinato, B. (1969). Cancer Chemotherapy Reports, 53, 33 .

Hewlett, J. S., et al. (1964). Cancer Chemotherapy Reports, 42, 25. Holton C. P., et al. (1969). New England fournal of Medicine, 280, 171 .

Karnofsky, D. A. (1961). Clinical Pharmacology and Therapeutics, 2, 709.

Macrez, C., Marneffe-Lebrequier, H., Ripault, J., Clauvel, J. P., Jaquillat, C., and Weil M. (1967). Pathologie et Biologie, 15, 949.

Malpas, J. S., and Scott, R. B. (1968). British Medical fournal, 3, 227. Malpas, J. S., and Scott, R. B. (1969). Lancet, 1, 469.

Marmont, A. M., Damasio, E., and Rossi, F. (1969). Lancet, 1, 837. Marm, C., Tasaka, H., Yu, K. P., Murphy, L., and Karnofsky, D. A.
(1967). Cancer, 20, 333 . 